\title{
Great apes' performance in discriminating weight and achromatic color
}

\author{
Cornelia Schrauf $\cdot$ Josep Call
}

Received: 8 September 2008 / Revised: 30 January 2009 / Accepted: 5 February 2009 / Published online: 24 February 2009

(C) The Author(s) 2009. This article is published with open access at Springerlink.com

\begin{abstract}
Much work has been done on visual discrimination in primates over the past decade. In contrast, very little is known about the relevance of non-visual information in discrimination learning. We investigated weight and achromatic color (color, henceforth) discrimination in bonobos, gorillas and orangutans, using the exchange paradigm in which subjects have to give objects to the experimenter in order to receive a reward. Unlike previous studies, subjects were not trained to lift objects because lifting the objects was an integral part of the exchange procedure. This methodology also allowed us a direct comparison between visual and weight discrimination. We presented 12 subjects (5 bonobos, 2 gorillas and 5 orangutans) with two sets of objects corresponding to two conditions. The objects in the color condition (white/black) differed only in color and those in the weight condition (light/heavy) differed only in weight. Five apes learned to discriminate weight and six to discriminate color. Subjects learned color discrimination faster than weight discrimination. Our results suggest that bonobos and orangutans are sensitive to differences in weight and able to learn discriminating objects that differ in this property.
\end{abstract}

Keywords Discrimination learning - Kinesthetic perception $\cdot$ Weight discrimination

C. Schrauf $(\bowtie)$

Department for Neurobiology and Cognition Research, University of Vienna, Althanstrasse 14, Vienna 1090, Austria

e-mail: conny.schrauf@ chello.at

J. Call

Max Planck Institute for Evolutionary Anthropology,

Leipzig, Germany

\section{Introduction}

Foraging efficiently depends to a great extent on the ability to acquire and process information about environmental stimuli. The senses are a main way to acquire this information to make efficient foraging decisions (Gibson 1966, 1979; Gibson KR 1986). Moreover, repeated exposure to the same stimuli and their consequences foster learning, which in turn, increase the probability of making optimal foraging decisions.

Primates have traditionally been considered to be primarily visually oriented animals (Fobes and King 1982), relying on their highly developed visual system to optimize their foraging efficiency and avoid toxic substances. However, the olfactory, auditory and proprioceptory senses also play an important role in acquiring relevant information for food selection (Dominy et al. 2001). This seems particularly important considering that a variety of plants and fruits change color or other visual features only a little if at all, during ripening or maturation (Nagy et al. 1980; Gautier-Hion et al. 1985). In fact, in some primate species vision plays only a secondary role in food acquisition. For example, the aye-aye finger taps wood with its finger to produce auditory information in order to locate cavities under the surface (Erickson 1991). Wild-tufted capuchin monkeys locate frogs hiding inside the guadue plant by listening for particular sounds (Izawa 1978). Nut-cracking chimpanzees and capuchin monkeys have to rely on nonvisual cues (smell, weight, sound) in order to assess the state of a nut, because the protective shell prevents visual assessment of its contents (for a more detailed description, see Visalberghi and Néel 2003). As cracking open a nut is a costly behavior, both in terms of time and energy, it seems worthwhile to open a nut only when it contains the energyrich kernel inside and not when the kernel has dried 
(Boesch and Boesch 1983; Boinski et al. 2003). Therefore, it seems reasonable to assume that primates would use a variety of sensory modalities to evaluate and learn about potential food sources.

We know a fair amount about vision as a way to identify stimuli associated with food. Visual acuity and color perception are well developed in primates (Spence 1934; Grether 1940a, b; Tigges 1963; Tigges and Tigges 1965; Davis and Markowitz 1978; Barbiers 1985; Vonk 2003; Buchanan-Smith 2005).

Furthermore, numerous studies have investigated visual discrimination learning in primates using cues such as color, brightness, shape and size (Jarvik 1953; Fobes and King 1982; Rumbaugh and Pate 1984). Naïve individuals typically require dozens of trials to associate a particular object with the presence of a reward, although other studies show that individuals can detect the presence of novel objects in their enclosure quite readily (Menzel and Juno 1982). Additionally, most studies investigating problem solving of various types (e.g., tool use, inferences, computerized tasks) have relied on the use of visual information (Tomasello and Call 1997; Matsuzawa et al. 2006). Even those studies that have investigated whether individuals can make inferences about food location based on the notion of weight have relied on visual information to present the task (Hanus and Call 2008).

In contrast to the wealth of knowledge available on the use of visual information in primates, we know much less about the use of other sensory modalities. This is especially true of their kinesthetic abilities, for instance, with regard to weight discrimination. To the best of our knowledge, there are only two published studies in this area. McCulloch (1941) trained five chimpanzees to select the heavier of two boxes. Despite the large weight differences ( 80 vs. $480 \mathrm{~g}$ or 80 vs. $640 \mathrm{~g}$ ), the chimpanzees needed a median of 1,100 trials to master the task. Once the subjects were successful in their performance, the weight of the heavier box was decreased. The smallest weight difference that the chimpanzees were able to discriminate between was $4 \mathrm{~g}$ (80 vs. $84 \mathrm{~g})$.

Klüver (1933) also conducted weight discrimination experiments with monkeys. Subjects were presented with two boxes differing in weight (450 vs. $150 \mathrm{~g}$ ) and were required to compare their weights and select the correct alternative: some subjects needed to select the heavier box while others were required to select the lighter box. Longtailed macaques and spider monkeys took a median of 586 and 330 trials, respectively, to reach an errorless performance whereas a capuchin monkey required 321 trials. Moreover, species varied in the weight difference between quantities that they required in order to see signs of successful discrimination (long-tailed macaques: $750 \mathrm{~g}$; spider monkeys: $900 \mathrm{~g}$; capuchin monkey: $600 \mathrm{~g}$ ). Thus, these two studies indicate that subjects of various species are able to discriminate weight, but it took them hundreds of trials to reach criterion even though there were considerable weight differences between quantities.

One might conclude, based on this evidence, that visual discrimination is easier than weight discrimination, thus reinforcing the idea of a visual-sensory primacy in monkeys and apes. However, caution is warranted when comparing experiments on visual and weight discrimination because they used different methods. Additionally, only a total of 11 individuals (belonging to 4 different species) have been tested on weight discrimination compared to hundreds of individuals from dozens of species that have been tested on visual discrimination. It is, therefore, essential to study the use of non-visual information to get a more balanced view of discrimination learning with nonvisual stimuli. Such information can be used to design more complex problem-solving tasks that do not rely solely on visual input (e.g., Povinelli and Dunphy-Lelii 2001) and to gain some insights about the use of weight to assess the suitability of stone hammers to crack open nuts (Boesch and Boesch 1983; Visalberghi et al. 2007; Schrauf et al. 2008).

The aim of the current study was to evaluate how great apes, other than chimpanzees, perform in a weight discrimination task. To date nothing is known about the ability of gorillas, orangutans and bonobos to use weight information. For this purpose, we employed a method in which, unlike previous studies (Klüver 1933; McCulloch 1941; Schrauf et al. 2008), subjects lifted the objects spontaneously, without the need to offer an incentive to do so. Furthermore, the methodology used here allowed us to directly compare visual discrimination in the form of an achromatic color (color, henceforth) discrimination task. This means that we were able to assess the putative superiority of visual over kinesthetic information. Additionally, the inclusion of this visual discrimination task served as a control for the procedure because we expected that subjects would be able to solve at least the color discrimination task within the allocated number of trials.

\section{Method}

\section{Subjects}

Five orangutans (Pongo pygmaeus abelii), three gorillas (Gorilla gorilla gorilla) and five bonobos (Pan paniscus) housed at the Wolfgang Köhler Primate Research Centre, Leipzig Zoo (Germany) participated in this study. There were 8 females and 4 males with ages ranging from 11 to 33 years (for a more detailed description, please refer to Table 1). All subjects lived in social groups of various sizes 
Table 1 Participants of the exchange experiment

\begin{tabular}{|c|c|c|c|c|c|c|c|c|}
\hline \multirow[t]{2}{*}{ Species } & \multirow[t]{2}{*}{ Subject } & \multirow[t]{2}{*}{ Sex } & \multirow[t]{2}{*}{ Age } & \multicolumn{2}{|c|}{ Color condition } & \multicolumn{2}{|c|}{ Weight condition } & \multirow[t]{2}{*}{ Order } \\
\hline & & & & Correct & Session & Correct & Session & \\
\hline Orang & Padana & Female & 8 & White & 36 & Light & 30 & $b-w$ \\
\hline Orang & Pini & Female & 18 & Black & 36 & Light & 32 & $\mathrm{~b}-\mathrm{w}$ \\
\hline Orang & Dokana & Female & 17 & Black & 14 & Heavy & 36 & $b-w$ \\
\hline Orang & Dunja & Female & 33 & White & 36 & Heavy & 36 & $\mathrm{w}-\mathrm{b}$ \\
\hline Orang & Bimbo & Male & 26 & White & 36 & Light & 36 & $\mathrm{w}-\mathrm{b}$ \\
\hline Bonobo & Joey & Male & 23 & Black & 29 & Heavy & 36 & b-w \\
\hline Bonobo & Limbuko & Male & 10 & Black & 6 & Light & 14 & $\mathrm{w}-\mathrm{b}$ \\
\hline Bonobo & Kuno & Male & 9 & White & 3 & Light & 9 & $\mathrm{w}-\mathrm{b}$ \\
\hline Bonobo & Ulindi & Female & 12 & White & 4 & Heavy & 35 & $b-w$ \\
\hline Bonobo & Yasa & Female & 9 & Black & 36 & Heavy & 36 & $\mathrm{w}-\mathrm{b}$ \\
\hline Gorilla & Bebe & Female & 26 & Black & 7 & Heavy & 36 & $\mathrm{w}-\mathrm{b}$ \\
\hline Gorilla & Viringika & Female & 11 & Black & 36 & Heavy & 36 & b-w \\
\hline
\end{tabular}

Numbers in bold indicate successful performance. Correct: type of correct stimulus, session: session number in which the criterion (6 out of 6 correct choices) was reached. Order: order in which the two tests were performed (b-w: subjects were first tested for color and thereafter for weight, w-b: vice versa)

in indoor and outdoor compounds. Prior to this study, subjects had participated in a number of cognitive experiments including visual discrimination of shape, size, and color (e.g., Vlamings et al. 2006) but had never been tested on weight discrimination. The selection of subjects was based on their preexisting experience in exchanging objects for rewards with a human experimenter (see Pelé et al. 2009), which represented an integral part of our current procedure. During the experiment, the subjects were separated from their group members and individually tested in their indoor cages.

\section{Materials}

Subjects were presented with two sets of objects. For the weight discrimination condition, we used 12 grey PVC cylinders $(9.5 \mathrm{~cm} \times 4 \mathrm{~cm})$ of identical outward appearance. Six of the cylinders were filled with lead shot, weighing a total of $400 \mathrm{~g}$. The other remaining six were empty, and each weighed $100 \mathrm{~g}$. A transparent silicone paste was added to incorporate the contents in a solid and homogenous mass, preventing any rattling noise during manipulations and evenly distributing the weight throughout the tool. For the color condition, we presented 12 colored PVC rectangles $(8 \mathrm{~cm} \times 3.5 \mathrm{~cm} \times 1.5 \mathrm{~cm})$. Six of the rectangles were black and the remaining six were white. The objects were placed inside the subjects' cage in alternate order (see Fig. 1). A blue and a white bowl were placed in front of the cage on the ground. We used grapes as rewards for all the subjects except Bimbo, a male orangutan, who received monkey chow instead.

\section{Procedure}

The experiment was conducted within the framework of the exchange paradigm (Hyatt and Hopkins 1998) in which subjects had to exchange objects with a human experimenter. In our study, the apes had to return objects with a certain feature to the experimenter to obtain a food reward. The advantage of the exchange paradigm was that the act which was needed in order to assess the critical property (lifting the object) was a part of the procedure. In particular, giving the experimenter the objects that were placed inside the subjects' cage necessarily involved lifting them prior to the exchange. Thus neither an incentive nor training was needed for the subjects to lift the objects in order to perceive kinesthetic cues.

Before the apes entered the testing room the objects were positioned inside the subjects' cage on a ledge by one of the research panels (see Fig. 1). The experimenter was sitting outside the cage facing the subject. To exclude inadvertent cueing while the subject was selecting the objects, an opaque panel prevented the experimenter from seeing the subjects. Only after the subject had handed the selected item to the experimenter, and thus had already made its choice, the experimenter could see or feel if it was the correct one. This means that apes could not receive experimenter-given cues regarding the objects' value. Below the opaque panel, a wire mesh divider allowed the exchange of objects for rewards between the experimenter and the subject. The experimenter requested an item by extending her hand, palm-up (begging gesture), in front of the wire mesh. If the subject returned a correct item, the experimenter 
Fig. 1 Experimental set-up for the exchange experiment: exchange objects are placed on a ledge inside the ape's cage. The experimenter shows a reward that will be given to the subject after it has returned a correct object. a Ape lifts an object. b Ape gives an object to the experimenter. Drawing by Sandra Michaelis
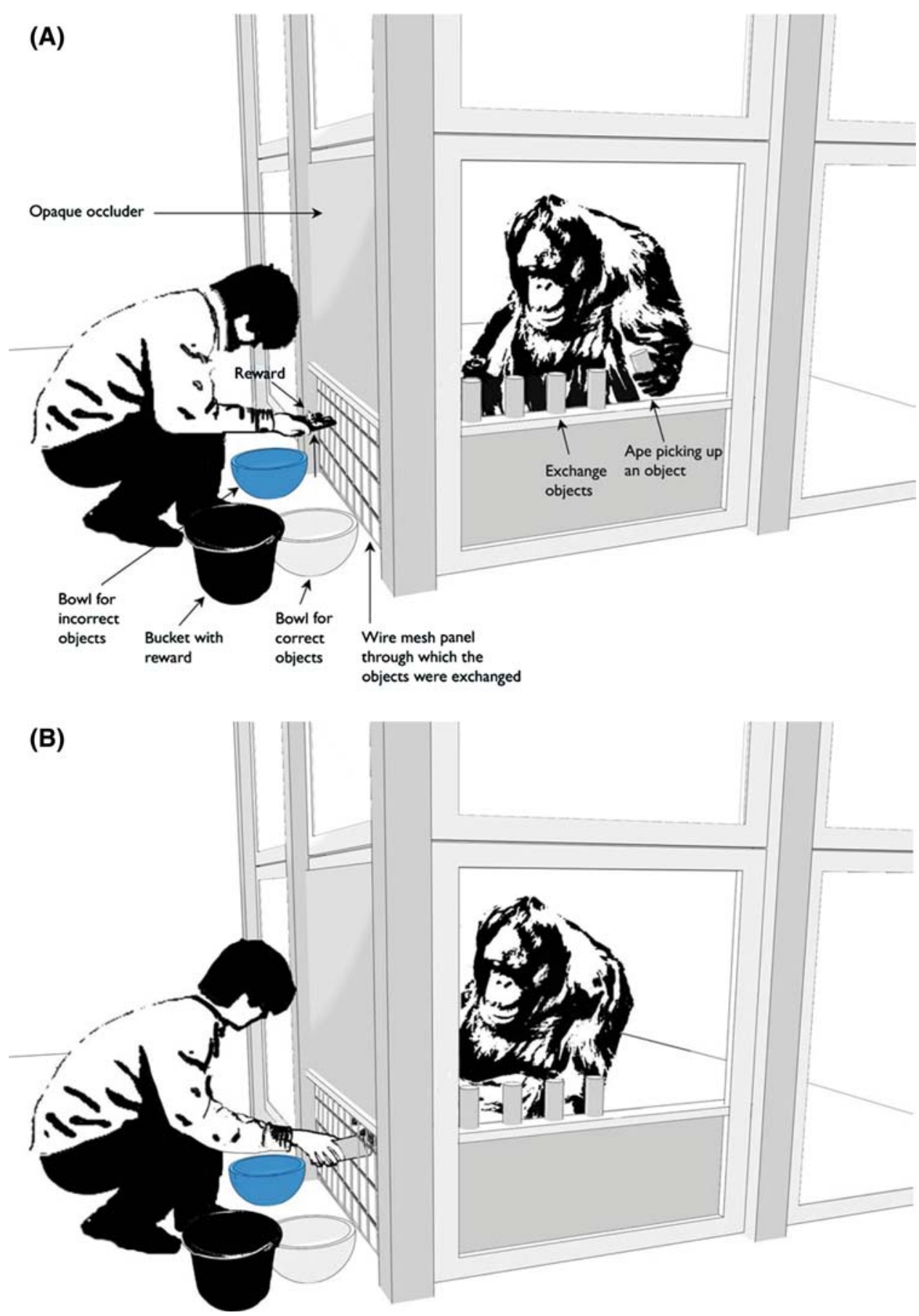

dropped it in the white bowl on her right and gave a reward to the subject. If the subject returned an incorrect object the experimenter dropped it in the blue bowl on her left and gave no reward.

Subjects were presented with two sets of objects corresponding to two conditions. In the color condition (white/ black) the items differed only in achromatic color; in the weight condition (heavy/light) they differed only in weight. Prior to testing, we decided which feature (black or white; heavy or light) would be regarded to be correct for each sub- ject. This selection was done arbitrarily, e.g., there was no obvious reason for the apes why black or white (heavy or light) should be correct and counterbalanced across subjects.

Each subject received two sessions per day. A session lasted until all six correct objects had been returned to the experimenter. Everyday after the first session, the ape was moved to an adjacent cage to allow the experimenter to reposition the objects for the following session. Subjects were tested until they either reached the criterion for errorless performance (see below) or had received 36 sessions. 
Data scoring and analysis

We videotaped all the trials and scored them live on a check sheet. We used the videotapes to verify the original scoring. We coded the identity of the objects returned by the subjects. The criterion for successful performance consisted of returning all six correct objects in their first six attempts during a given session (errorless performance). As the probability for such a result to occur when the objects are returned randomly is 0.001 for a single session and the combined probability for the whole test of 36 sessions is 0.039 , we considered this criterion as sufficient.

We used non-parametric statistics to analyze the data. In particular, we compared the number of subjects that solved each task (sign test) and the number of sessions needed to discriminate color and weight (Wilcoxon test). Additionally we assessed the effect of the order of task presentation and the type of stimuli on performance (Fisher's test). Finally, we tested whether bonobos and orangutans differed in weight and color discrimination (Mann-Whitney $U$ test). Gorillas were not included in the species comparison because of our small $(N=2)$ sample size. All tests were two tailed.

\section{Results}

Five of the 12 subjects tested performed above chance in the weight discrimination condition (see Table 1). They needed a median of 30 sessions (331 exchanges) to reach the criterion of 6 out of 6 correct exchanges. Six of the 12 apes solved the color discrimination with a median of 6.5 sessions (64 exchanges). The remaining subjects showed no improvement in performance until the end of the experiment (session 36). Only three subjects learned to discriminate both color and weight. A comparison of the number of subjects that solved color versus weight revealed no significant difference using the sign test $(N=3 ; P>0.99)$. However, when all subjects were taken together as a group they seemed faster at discriminating color than weight (Wilcoxon test $Z=-2.033 ; N=12 ; P<0.042$ ).

Subjects learned the color discrimination in both caseswhen white or black was the positive stimulus. Likewise weight discrimination was also learned on both instances independently if heavy or light was regarded to be correct. Neither the type of positive stimulus nor the order of presentation of conditions had a significant influence on the subjects' performance in either the color discrimination task (Fisher exact tests: type, $P>0.99$; order, $P>0.99$ ) or the weight discrimination task (Fisher exact tests: type, $P=0.072$; order, $P>0.99$ ). There were no significant differences in performance between bonobos and orangutans in either the color (Mann-Whitney $U$ test $U=4$;
$N=10 ; P=0.058)$ or weight discrimination conditions (Mann-Whitney $U$ test $U=9 ; N=10 ; P=0.435$ ). Because of the small sample size $(N=2)$, the gorillas were not included in the analysis for species differences. One gorilla (Bebe) learned to discriminate color within seven sessions. However, in the weight discrimination condition she showed no improvement in performance until the end of the experiment (36 sessions).

\section{Discussion}

Some of our bonobos and orangutans learned to discriminate between differences in weight; however, they learned color faster than weight discrimination. We found no evidence of significant differences between bonobos and orangutans concerning weight discrimination. None of the two gorillas learned the weight discrimination task but the small sample size precluded a direct comparison with the other species.

It may seem surprising that most of the subjects did not master the weight or color discrimination task. A lack of motivation for this outcome seems unlikely because even unsuccessful subjects continued to return objects at every opportunity and yet showed neither an increase nor a decrease in their performance over the course of the experiment. Similarly, a failure to understand the task is also unlikely because all subjects had been fully trained in the exchange procedure prior to the current study. Perhaps this result is not so surprising if one considers that learning to associate an arbitrary cue such as color or weight with a reward is not a trivial task for great apes (Call 2006). Naïve apes may take dozens of trials (if not more) to master a seemingly easy task such as choosing between two alternatives presented on a platform (Spence 1937; Jarvik 1953; Rumbaugh and Rice 1962; Davis and Markowitz 1978).

Compared to previous studies, orangutans and bonobos required a much smaller number of sessions to reach the weight discrimination criterion than chimpanzees and monkeys (Klüver 1933; McCulloch 1941). This difference is also true when comparing the number of exchanges/trials in both sets of studies (median of 331 exchanges in our study/ median of 1,100 trials in McCulloch's experiment). A direct comparison with the monkeys' performance tested by Klüver is problematic because the author enlarged the weight differences until the first sign of learning occurred; however, the monkeys needed a median of 414.5 trials to reach an errorless performance. One possible explanation for this difference is that the species differed in their ability to discriminate weight. Alternatively, differences in the method employed in order to assess weight discrimination could explain these differences. In particular, the exchange method used in the current study meant that no training was 
required to lift the objects -subjects did so within the context of the task; thus, the apes' task consisted of perceiving and associating the discriminative feature that was associated with reinforcement. One final explanation has to do with inter-individual differences, which were important in our study. Such large inter-individual differences paired with small sample sizes could potentially explain some of the differences observed between studies. It is currently unclear which of these three alternatives is responsible or may have contributed to a greater degree to the observed differences. Future studies based on the exchange method, comparing the primate species included in previous studies, will be needed in order to tease apart these alternatives.

We found some evidence that subjects were faster at discriminating color than weight. Unlike previous studies, this difference cannot be attributed to the use of different methodologies to test each perceptual modality. This would seem to reinforce the notion of a primacy of visual over kinesthetic information, at least in the case of bonobos and orangutans. At this point it is important to note that all of our apes were naïve to weight experiments but had participated earlier in experiments involving visual discrimination. This difference might therefore have influenced the subjects' performance and it remains possible that apes would have been faster when given experience with weight before. Therefore, it is conceivable that the putative superiority of visual over kinesthetic cues reflected an effect of practice.

A remarkable observation from the experiment should be mentioned. All subjects that were able to solve the weight discrimination condition started to divide the objects according to its weight. In particular, whenever an incorrect item was chosen (touched with the finger or lifted), the subjects placed it on the ground in front of them. On one instance, a female orangutan placed all the incorrect items in front of her on a piece of cardboard that she had brought with her before entering the testing room. Because an object's weight is only perceived by lifting it in this study, this behavior could have been a strategy to help keep track of the objects that were not rewarded, thereby allowing them to distinguish those objects more readily from the others. On the occasions when the subjects had also placed correct items on the ground, we observed that they would lift each object off the ground until the correct item was found. However, this behavior became less frequent over time.

Although apes can sort objects into distinct groups if trained to do so (Premack 1976; Garcha and Ettlinger 1979; Savage-Rumbaugh 1986; Matsuzawa 1990; Spinozzi 1993; Tanaka 1995), they rarely do so spontaneously (Tomasello and Call 1997, but see Hayes and Nissen 1971 for a notable exception on an enculturated chimpanzee). However, in the present study the apes-without any specific sorting train- ing or special rearing history—spontaneously separated items spatially according to weight. It is highly possible that they did so to keep track of the objects' identity in the absence of any discriminative visual cues. This explanation is further reinforced by a similar finding on hammer selection by a capuchin monkey (Schrauf et al. 2008). This individual lifted the potential hammers, which were similar in outward appearance, and placed the heavier (most efficient) one close to him, often holding it with his foot. In contrast, the lighter tools were placed either back or sideways away from him. Schrauf et al. (2008) concluded that this advantageous strategy allowed the capuchin monkey to keep track of the heavy tool. Coming back to the current experiment, it would be interesting to see whether apes would spontaneously make different piles of visually undistinguishable objects based on their weight while the experimenter was absent, in anticipation of her returning at a later time. This would not only show that apes sort objects spontaneously when the situation requires them to do so but that they could also plan for the occurrence of future events (e.g., the arrival of the experimenter)-something that has been recently reported in the great apes (Mulcahy and Call 2006; Dufour and Sterck 2008; Osvath and Osvath 2008) and corvids (Raby et al. 2007). This form of planning involving the execution of a number of actions in preparation for a particular goal has been described as planning for action. An analogous situation has been reported in dolphins gathering multiple weights and placing them at a particular location in preparation to solve a task (Kuczaj and Walker 2006). Chimpanzees and capuchin monkeys have also been observed to bring nuts and tools to an anvil to crack open the nuts (Boesch and Boesch 1984; Visalberghi et al. 2007).

Perhaps one of the most important contributions of this study is that it calls attention to the use of kinesthetic information in testing cognition in primates and other animals. This is important because most studies have relied on tasks with a predominant visual component and less attention has been given to non-visual modalities when presenting problems. This is even more remarkable given the reported observations on nut cracking in chimpanzees and capuchins who use weight as a key feature for the selection of hammers to crack open nuts (Boesch and Boesch 1983; Visalberghi et al. 2007; Schrauf et al. 2008). Bril et al. (2008) reported that captive chimpanzees changed their nut-cracking behavior according to the weight of the hammers provided to them. Similarly, Biro et al. (2006) found that wild chimpanzees choice to use a stone as an anvil or a hammer was affected by its weight. Our study has shown that utilizing weight information is readily done by bonobos and orangutans, and that is picked up much faster than it has been shown in previous studies. This is the prerequisite for other tasks such as hammer selection in which weight is a 
functional feature. An important distinction has to be made between the relation between weight and reward delivery in discrimination tasks (like the current one) and the hammer selection tasks (Call 2006). In discrimination tasks, weight and reward hold an arbitrary relation, i.e., there is no reason (other than the experimenter's choice) why 'heavy' should be associated with reward delivery. In contrast, in hammer selection tasks, there is a physico-causal reason (having to do with force) as to why heavy hammers are more effective than lighter ones. Detecting weight differences between stimuli is the first step and the prerequisite to presenting more complex problem-solving tasks based on a richer causal structure.

The distinction between arbitrary and causal relations between stimuli is not restricted to weight appreciation (Hanus and Call 2008) but it extends to other domains including a naïve appreciation of solidity, gravity, and collision (Call 2004, 2007; Martin-Ordas and Call 2009; Martin-Ordas et al. 2008; Bania et al. 2009). Most of these studies are based on visual information but it is conceivable that future studies will document the arbitrary versus causal relation in the kinesthetic modality. For instance, one could investigate whether subjects could infer the presence of a reward in one of two opaque cups based on its weight. Provided that both cups are identical and the reward is placed in one of the cups, the heavier of the two cups should hold the reward. One would predict that subjects would be much faster at solving tasks with a causal structure than an arbitrary one. Recently, Hanus and Call (2008) showed that chimpanzees were able to infer the location of a reward based on the effect that its weight had on a balance beam. Nevertheless, in this study the information about the effect of weight was visual rather than kinesthetic.

The use of information about weight may not be the only kinesthetic information that subjects may successfully use to solve complex problems. Seed (2007) presented five chimpanzees with functional and non-functional trap tubes. One subject, Alexandra, developed a strategy in which she inspected both traps of the apparatus with her fingers before responding. She started to do so after an incorrect response and continued this behavior after every error. Interestingly, Alexandra was the only subject that could solve the task. It is therefore conceivable that the chimpanzee's good performance was influenced by the acquisition of tactile information. Thus, although monkeys and apes are primarily visual animals, other senses (e.g., tactile) also play a major role to gain relevant information from the environment and can be a suitable channel to pose some questions about complex problem solving.

In conclusion, the current study demonstrated that bonobos and orangutans were sensitive to differences in weight between two otherwise identical objects. We think that this kinesthetic ability is of importance as the animals might apply such knowledge to different situations such as tool use and tool production or when making inferences about the physical environment. This study also showed the importance of the employed method to measure a certain variable. Whereas in previous studies the chimpanzees needed approximately 1,000 trials (McCulloch 1941) to reach criterion, the apes in our study learned much faster, although all of them were naïve to weight experiments. The advantage of the exchange paradigm was that the act needed to assess the critical property, namely, lifting the object, was already part of the exchange routine. Further studies in different contexts are needed for a better understanding as to what extent apes can make use of weight information and how this guides their problem-solving behavior.

Acknowledgments This research was supported by a grant (DOC fFORTE) from the Austrian Academy of Science to Cornelia Schrauf. We thank Bernhard Voelkl for statistical advice and helpful comments on the manuscript, Nathan Pyne-Carter for improving the English and Sandra Michaelis for her drawing of the experimental set-up. The reported experiments comply with all laws of the country in which they were performed.

Open Access This article is distributed under the terms of the Creative Commons Attribution Noncommercial License which permits any noncommercial use, distribution, and reproduction in any medium, provided the original author(s) and source are credited.

\section{References}

Bania AE, Harris S, Kinsley HR, Boysen ST (2009) Constructive and deconstructive tool modification by chimpanzees (Pan troglodytes). Anim Cogn 12:85-95

Barbiers RB (1985) Orangutans' color preference for food items. Zoo Biol 4:287-290

Biro D, Sousa C, Matsuzawa T (2006) Ontogeny and cultural propagation of tool use by wild chimpanzees at Bossou, Guinea: case studies in nut cracking and leaf folding. In: Matsuzawa $\mathrm{T}$, Tomonaga M, Tanaka M (eds) Cognitive development in chimpanzees. Springer, Tokyo, pp 476-508

Boesch C, Boesch H (1983) Optimization of nut cracking with natural hammers by wild chimpanzees. Behaviour 83:265-286

Boesch C, Boesch H (1984) Mental map in wild chimpanzees: an analysis of hammer transports for nut cracking. Primates 25:160-170

Boinski S, Quatrone RP, Sughrue K, Selvaggi L, Henry M, Stickler CM, Rose LM (2003) Do brown capuchins socially learn foraging skills? In: Fragaszy DM, Perry S (eds) The biology of traditions: models and evidence. Cambridge University Press, Cambridge, pp 365-390

Bril B, Dietrich G, Foucart J, Fuwa K, Hirata S (2008) Tool use as a way to assess cognition: how do captive chimpanzees handle the weight of the hammer when cracking a nut? Anim Cogn. doi:10.1007/s10071-008-0184-x

Buchanan-Smith HM (2005) Recent advances in color vision research. Am J Primatol 67:393-398

Call J (2004) Inferences about the location of food in the great apes (Pan paniscus, Pan troglodytes, Gorilla gorilla, Pongo pygmaeus). J Comp Psychol 118:232-241

Call J (2006) Descartes' two errors: reasoning and reflection from a comparative perspective. In: Hurley S, Nudds M (eds) Rational animals. Oxford University Press, Oxford, pp 219-234 
Call J (2007) Apes know that hidden objects can affect the orientation of other objects. Cognition 105:1-25

Davis RR, Markowitz H (1978) Orangutan performance on a lightdark reversal discrimination in the zoo. Primates 19:755-759

Dominy NJ, Lucas PW, Osorio D, Yamashita N (2001) The sensory ecology of primate food perception. Evol Anthropol 10:171-186

Dufour V, Sterck EHM (2008) Chimpanzees fail to plan in an exchange task but succeed in a tool-using procedure. Behav Process 79:19-27

Erickson CL (1991) Percussive foraging in the aye-aye, Daubentonia madagascariensis. Anim Behav 41:793-801

Fobes JL, King JE (eds) (1982) Primate behavior. New York Academic Press, New York

Garcha HS, Ettlinger G (1979) Object sorting by chimpanzees and monkeys. Cortex 15:213-224

Gautier-Hion A, Duplantier JM, Quris R, Feer F, Sourd C, Decoux JP, Dubost G, Emmons L, Erard C, Hecketsweiler P, Moungazi A, Roussilhon C, Thiollay JM (1985) Fruit characters as a basis of fruit choice and seed dispersal in a tropical forest vertebrate community. Oecologia (Berl) 65:324-337

Gibson JJ (1966) The senses considered as perceptual systems. Houghton-Mifflin, Boston

Gibson JJ (1979) The ecological approach to visual perception. Houghton-Mifflin, Boston

Gibson KR (1986) Cognition, brain size and the extraction of embedded food resources. In: Else JG, Lee PC (eds) Primate ontogeny, cognition, and social behaviour. Cambridge University Press, Cambridge, pp 93-103

Grether WF (1940a) A comparison of human and chimpanzee spectral hue discrimination curves. J Exp Psychol 26:394-403

Grether WF (1940b) Chimpanzee color vision. I. Hue discrimination at three spectral points. J Comp Psychol 29:167-192

Hanus D, Call J (2008) Chimpanzees infer the location of a reward based on the effect of its weight. Curr Biol 18:370-371

Hayes KJ, Nissen CH (1971) Higher mental functions of a home-raised chimpanzee. In: Schrier AM, Stollnitz F (eds) Behavior of nonhuman primates. Academic Press, New York, pp 59-115

Hyatt CW, Hopkins WD (1998) Interspecies object exchange: bartering in apes? Behav Proc 42:177-187

Izawa K (1978) Frog-eating behaviour of wild-capped capuchin (Cebus apella). Primates 19:633-642

Jarvik ME (1953) Discrimination of colored food and food signs by primates. J Comp Psychol 46:390-392

Klüver H (1933) Behavior mechanisms in monkeys. Chicago University Press, Chicago

Kuczaj SA II, Walker RT (2006) How do dolphins solve problems? In: Wasserman EA, Zentall TR (eds) Comparative cognition: experimental explorations of animal intelligence. Oxford University Press, New York, pp 580-600

Martin-Ordas G, Call J (2009) Assessing generalization within and between trap tasks in the great apes. Int J Comp Psychol (in press)

Martin-Ordas G, Call J, Colmenares F (2008) Constructive and deconstructive tool modification by chimpanzees (Pan troglodytes). Anim Cogn 11:423-430

Matsuzawa T (1990) Spontaneous sorting in human and chimpanzee. In: Parker ST, Gibson KR (eds) Language and intelligence in monkeys and apes. Cambridge University Press, Cambridge

Matsuzawa T, Tomonaga M, Tanaka M (2006) Color recognition in chimpanzees (Pan troglodytes). In: Matsuzawa T, Tomonaga M, Tanaka M (eds) Cognitive development in chimpanzees. Springer, Tokyo

McCulloch (1941) Discrimination of lifted weights by chimpanzees. J Comp Psychol 32:507-519
Menzel EW Jr, Juno C (1982) Marmosets (Saguinus fuscicollis): are learning sets learned? Science 217:750-752

Mulcahy NJ, Call J (2006) Apes save tools for future use. Science 312:1038-1040

Nagy S, Shaw PE, Wardowski WF et al (1980) Fruits of tropical and subtropical origin: composition, properties and uses. Florida Science Source, Lake Alfred, pp 302-321

Osvath M, Osvath H (2008) Chimpanzee (Pan troglodytes) and orangutan (Pongo abelii) forethought: self-control and pre-experience in the face of future tool use. Anim Cogn 11:661-674

Pelé M, Dufour V, Thierry B, Call J (2009) Token transfers among great apes: species differences, gestural requests and reciprocal exchange. J Comp Psychol (in press)

Povinelli DJ, Dunphy-Lelii S (2001) Do chimpanzees seek explanations? Preliminary comparative investigations. Can J Exp Psychol 55(2):187-195

Premack D (1976) Intelligence in ape and man. Lawrence Erlbaum, Hillsdale

Raby CR, Alexis DM, Dickinson A, Clayton NS (2007) Planning for the future by western scrub-jays. Nature 445:919-921

Rumbaugh DM, Pate JL (1984) Primates' learning by levels. In: Greenberg G, Tobach E (eds) Behavioral evolution and integrative levels. Lawrence Erlbaum, Hillsdale, pp 221-240

Rumbaugh DM, Rice CP (1962) Learning-set formation in young great apes. J Comp Phys Psychol 55:866-868

Savage-Rumbaugh ES (1986) Ape language. Columbia University Press, New York

Schrauf C, Huber L, Visalberghi E (2008) Do capuchin monkeys use weight to select hammer tools? Anim Cogn 11:413-422

Seed A (2007) Cognition in rooks and chimpanzees: a case of convergent evolution? Ph.D. thesis, Cambridge University, Cambridge

Spence KW (1934) Visual acuity and its relation to brightness in chimpanzee and man. J Comp Psychol 18:333-361

Spence KW (1937) Analysis of the formation of visual discrimination habits in chimpanzee. J Comp Psychol 23:77-100

Spinozzi G (1993) Development of spontaneous classificatory behaviour in chimpanzees (Pan troglodytes). J Comp Psychol 107:193200

Tanaka M (1995) Object sorting in chimpanzees (Pan troglodytes): classification based on physical identity, complementarity and familiarity. J Comp Psychol 109:151-161

Tigges J (1963) On color vision in gibbon and orangutan. Folia Primatol 1:188-198

Tigges J, Tigges M (1965) Ein Beitrag zur Farb- und Musterbevorzugung bei Gibbons und Orang-Utans. Zool Jb Physiol Bd 71:337344

Tomasello M, Call J (1997) Primate cognition. Oxford University Press, Oxford

Visalberghi E, Néel C (2003) Tufted capuchins (Cebus apella) use weight and sound to choose between full and empty nuts. Ecol Psychol 15:215-228

Visalberghi E, Fragaszy D, Ottoni E, Izar P, de Oliveira MG, Andrade FRD (2007) Characteristics of hammer stones and anvils used by wild bearded capuchin monkeys (Cebus libidinosus) to crack open palm nuts. Am J Phys 132:426-444

Vlamings PHJM, Uher J, Call J (2006) How the Great apes (Pan troglodytes, Pongo pygmaeus, Pan paniscus, and Gorilla gorilla) perform on the reversed contingency task: the effects of food quantity and food visibility. J Exp Psychol Anim Behav Process 32:60-70

Vonk J (2003) Gorilla (Gorilla gorilla gorilla) and orangutan (Pongo abelii) understanding of first- and second-order relations. Anim Cogn 6:77-86 